\title{
Treatment of Wastewater from Pulp and Paper Mill using Coagulation and Flocculation
}

\author{
Balpreet Kaur ${ }^{1 *}$, Rajeev Kumar Garg1, Anirudh Pratap Singh ${ }^{2}$ \\ ${ }^{1}$ Department of Chemical Engineering, ShaheedBhagat Singh State Technical Campus, Ferozepur, Punjab, India \\ ${ }^{2}$ Dean, Punjab Technical University, Jalandhar, Punjab, India
}

Received: 10/06/2020

Accepted: 21/10/2020

Published: 20/03/2021

\begin{abstract}
In this work, an effluent sample from a local medium-scale paper mill has been treated using alum as a coagulant and chitosan (natural polymer) as a flocculant. Initially, the dose of alum has been optimized by adjusting the zeta potential to near zero for best coagulation results. The dose of $0.04 \mathrm{~g} / \mathrm{L}$ was able to merely coagulate and unable to cause sweep flocculation of impurities. Then, at the optimised dose of $0.04 \mathrm{~g} / \mathrm{L}$ various concentrations of chitosan in the range of $0.1-0.5 \mathrm{~g} / \mathrm{L}$ were investigated for obtaining maximum flocculation of the suspended impurities. The physico-chemical parameters like $\mathrm{pH}$, total suspended solids (TSS), chemical oxygen demand (COD), absorbance, and zeta potential were studied for comprehending the flocculation behavior. The observed results exhibited that the maximum flocculation was achieved at the chitosan concentration of $0.3 \mathrm{~g} / \mathrm{L}$. At the flocculant concentration of $0.3 \mathrm{~g} / \mathrm{L}, 81 \%$ TSS removal and maximum $78 \%$ COD were reduced. Moreover, zeta potential value of the collected supernatant was close to zero ( $-1.49 \mathrm{mV})$ which showed larger floc formation and easy settleability of the impurities. In all, it can be said that the utilization of chitosan along with alum may be a better option for the treatment of pulp and paper wastewater as well as other similar types of wastewater.
\end{abstract}

Keywords: Pulp and paper mill waste water; coagulation-flocculation; chitosan; zeta potential; COD

\section{Introduction}

The environmental pollution due to the activities of small and medium-scale pulp and paper industries is multidimensional, causing serious problems not only to land fertility but also to the natural flora fauna as well as aquatic environment. The pulp and paper industry generates about 70 $120 \mathrm{~m}^{3}$ of wastewater per metric ton of paper produced $[1,2]$. Pulping is the initial step in paper making involving mechanical or chemical treatment of raw material. It is widely used for the separation of cellulose/hemi-cellulose fibers for attaining improvement in its papermaking properties [3]. Further, bleaching is carried out in multistage processes to remove the residual lignin and hence achieve whiteness and brightness in the pulp [4]. Both these steps are highly energy-intensive consuming enormous volumes of freshwater and involving usage of large quantities of chemicals which consequently affect the properties of discharged effluents [5]. Various studies authenticate the harmful and undesirable impacts of these chemicals [6-8]. These effluents have been responsible for generating color problems, algal growth, and scum formation which hamperthe aesthetic looks of the environment. Also the

*Corresponding author: Balpreet Kaur, Department of Chemical Engineering, Shaheed Bhagat Singh State Technical Campus, Ferozepur, Punjab, India. Email: balpreet_kaur@yahoo.com life of aquatic beings like zooplankton and fish is adversely affected due to release of toxic chemicals.

The use of cleaner technologies and incorporating modifications in the process design can potentially reduce the pollutant load from industrial wastewater. Nevertheless, waste generation cannot be completely eliminated. Therefore, alternative techniques need to be introduced which can meet the prescribed discharge limits for most affecting pollutants like COD, BOD, AOX, color, turbidity, etc. [9, 10]. In this respect, chemical coagulation and flocculation offer a promising solution to waste water treatment facilities [11]. In this technique salts of selective metals are added to wastewater which initially neutralize the charge on impurities and subsequently agglomerate them into larger flocs which can be easily removed by settling. The factors affecting the effectiveness of these techniques are the nature of coagulating agent, dose of coagulant, $\mathrm{pH}$ of solution, concentration, and nature of impurities present in wastewater. Generally, the pulp and paper mill effluents consist of many non-biodegradable, hydrophobic, and polar compounds specifically phenols, lignin, long-chain fatty acids, resinous acids, and aromatic compounds [12]. Almost all of these toxic compounds can be effectively removed through coagulation followed by flocculation.

In the past, many synthetic flocculants e.g. (PAM, HE, PEI) for precipitation of suspended impurities of paper mill waste water have been used [13]. The precipitated products obtained after the application of these flocculants have not been fully analyzed for degradation. It is expected that the precipitates are 
difficult to biodegrade as most of the flocculants are inorganic in nature or synthetic or polymeric materials which are itself difficult to biodegrade [14]. Chitosan a natural polymer obtained after partial deacetylation of chitin (biopolymer) has immense potential as a flocculant for wastewater treatment and sludge dewatering, as it is non-toxic, biodegradable, biocompatible and environment friendly [15-19]. Renault et al. [20] examined the flocculation behavior of cardboard mill wastewater collected after biological treatment with aerated lagoons using polyaluminium chloride (PAC) and chitosan solution. Flocculation tests indicated a drop of about $45 \%$ in COD and $\sim 65 \%$ in turbidity with PAC flocculant. On the other hand, flocculation using chitosan dissolved in acetic acid displayed a comparatively higher drop in COD $(\sim 80 \%)$ and turbidity ( $\sim 85 \%)$. Picos-Corrales et al. [21] studied the effect of chitosan and bean straw flour as bio-flocculants in the treatment of agricultural wastewater. Results from jar tests confirmed the higher efficiency of chitosan in the removal of pollutants and reducing the concentration of undesirable metals like manganese and iron from wastewater. However, both the materials performed better than the commercially available polyaluminium chloride coagulant. Altaher et al. [22] studied the effect of chitosan as a supporting coagulant along with conventional alum for sea water treatment. The combination of both (chitosan $5 \mathrm{mg} / \mathrm{L}$ and alum $13.5 \mathrm{mg} / \mathrm{L}$ ) was effective in reducing the turbidity from $1 \times 10^{4}$ to 10 NTU. Meraz et al. [23] investigated the behavior of two different molecular weights of chitosan on the coagulation-flocculation efficiency of tortilla industry waste water. Both the variants with dose less than $3 \mathrm{~g} / \mathrm{L}$ were successful in lowering the turbidity of water by $80 \%$ with $\mathrm{pH}$ of 5.5 maintained in the solution.

In the present study, chitosan is being used as a flocculant along with alum as a coagulant for the removal of suspended impurities from pulp and paper mill waste water. For a particular dose of alum, varying concentrations of bio-flocculant chitosan were examined for maximum removal of suspended and colloidal impurities from wastewater. Zeta potential of the supernatant before and after treatment with alum/chitosan was used as a yardstick for evaluating each procedure and understanding the colloidal behavior of suspended particles there in. Further, the reduction in the COD of waste water with addition of different concentrations of chitosan was determined. Also, the TSS, absorbance and $\mathrm{pH}$ of each solution before and post treatment with chitosan solution was investigated.

\section{Materials and methods \\ 2.1 Materials}

Wastewater was collected from the water treatment plant of a medium scale, agro residue, and recycle based paper mill in Punjab, India (details are not given due to confidentiality) with a production capacity of 200 tons/day. The major products produced by the mill are mechanical pulp, paper and board. The waste water samples collected were characterized and the results are given in Table 1. The measurement of these parameters was based on Standard Methods for the Examination of Water and Wastewater [24]. Aluminum potassium sulfate $\mathrm{AlK}\left(\mathrm{SO}_{4}\right)_{2} .12 \mathrm{H}_{2} \mathrm{O}$ (purity $99.9 \%$, $\mathrm{AR}$ grade), used as a coagulant in the study was purchased from CDH Pvt Ltd., India. Chitosan powderwas sourced from India Sea Foods, Cochin with ash content of $0.05 \%$.
Table 1: Chemical Characteristics of the wastewater collected from the paper mill

\begin{tabular}{ll}
\hline Parameters & Value \\
\hline COD $(\mathrm{mg} / \mathrm{L})$ & 2816 \\
$\mathrm{pH}$ & 6.51 \\
$\mathrm{TSS}(\mathrm{mg} / \mathrm{L})$ & 2029 \\
Zeta Potential $(\mathrm{mV})$ & -40 \\
Dissolved Oxygen $(\mathrm{ppm})$ & 0.8 \\
\hline
\end{tabular}

\subsubsection{Preparation of chitosan (bio-flocculant) solution}

Chitosan powder $(0.125 \mathrm{~g})$ was accurately weighed in a 250 $\mathrm{ml}$ volumetric flask and mixed thoroughly with $12.5 \mathrm{ml} \mathrm{HCL}$ $(0.1 \mathrm{M})$ solution and kept for one hour. The dissolution was slow and some amount of chitosan remained in the form of a thin gel. It was then diluted to $250 \mathrm{ml}$ with water to obtain a $0.5 \mathrm{~g} / \mathrm{L}$ chitosan $(\mathrm{CH})$ solution. After further dilutions five different concentrations $(0.1,0.2,0.3,0.4$ and $0.5 \mathrm{~g} / \mathrm{L})$ of chitosan solution were prepared. The solutions were freshly prepared before each set of experiments.

\subsection{Analytical methods}

COD tests were conducted on the supernatant collected after treatment of water sample with chitosan solution of various concentrations using closed reflux titrimetric method based on the APHA manual. To measure the charge on colloidal particles in waste water solutions NICOMP 380 ZLS (NICOMP Zeta potential/Particle Sizer, Santa Barbara, CA, USA) was used. The absorbance of various samples was recorded on UV-Vis double beam spectrophotometer (UV 5704SS), by Electronics Corporation of India. Samples were filtered with a glass filter before analysis using a quartz cuvette. $\mathrm{pH}$ meter (Eutech, Singapore) was used to measure the $\mathrm{pH}$ of all solutions. $\mathrm{pH}$ meter was calibrated with buffer solutions of $\mathrm{pH} 4, \mathrm{pH} 7$, and pH 9 before actual measurements. Magnetic stirrer model Remi, India was used for proper mixing of solutions. The total suspended solids (TSS) were evaluated with the use of standard filter paper (Whatman 42) and the residue retained on the filter was dried to a constant weight at 103 to $105{ }^{\circ} \mathrm{C}$ for $1 \mathrm{hr}$. The increase in weight of the filter represented the total suspended solids.

\section{Experimental section}

Five conical flasks of $250 \mathrm{ml}$ capacity with $100 \mathrm{ml}$ of wastewater sample in each were arranged for experimental study. Alum dose of $0.04 \mathrm{~g} / \mathrm{L}$ was added to each flask. To ensure uniform mixing the mixtures were stirred at $140 \mathrm{rpm}$ for 2 minutes. Then, $100 \mathrm{ml}$ of chitosan solution of different concentrations $(0.1,0.2,0.3,0.4$, and $0.5 \mathrm{~g} / \mathrm{L})$ was respectively added to five flasks and stirred thoroughly for 30 minutes at 40 rpm. It was kept undisturbed for half an hour for the settling of flocs. The $\mathrm{pH}$ was determined at this stage for each treated water sample. The supernatant was analyzed for investigating the various physico-chemical characteristics such as $\mathrm{pH}, \mathrm{COD}$, zeta potential, absorbance, and TSS.

\section{Results and discussion}

The mechanism involved in coagulation by alum follows two steps. Firstly, the positively charged hydroxyl groups attached to aluminum neutralize negatively charged particles 
present as impurities in waste water via adsorption and also affect their zeta potential. Besides, they also lower or remove the DLVO (Derjaguin, Landau, Verwey, and Overbeek) energy barrier. However, this step depends upon the dose of alum and the $\mathrm{pH}$ of the solution. In the second step, when the alum dose exceeds $0.03 \mathrm{~g} / \mathrm{L}$, the sweep flocculation starts predominating. Though there is no specific value for zeta potential that ensures effective coagulation for any waste water treatment plant, still value lying between -4 and $+3 \mathrm{mV}$ offers an optimum range for efficient coagulation [25]. For determining of the optimum dose of alum for coagulation of colloids of present water sample following experimentation was done.

\subsection{Effect of alum dose on zeta potential}

$100 \mathrm{ml}$ of waste water sample was individually filled in four conical flasks. Different amount of alum dose such as $0.02 \mathrm{~g} / \mathrm{L}$, $0.03 \mathrm{~g} / \mathrm{L}, 0.04 \mathrm{~g} / \mathrm{L}$, and $0.05 \mathrm{~g} / \mathrm{L}$ was added to each flask. The solutions were stirred at $140 \mathrm{rpm}$ for $2 \mathrm{~min}$. Thereafter, the zeta potential of each solution was measured. The values obtained are presented in Table 2 and the observed results are shown in Fig. 1.

Table 2: Variation in zeta potential of waste water samples with variation in alum dose

\begin{tabular}{ll}
\hline Alum dose (g/L) & Zeta potential $(\mathbf{m V})$ \\
\hline 0.02 & -31.82 \\
0.03 & -19.49 \\
$\mathbf{0 . 0 4}$ & $\mathbf{- 3 . 7 2}$ \\
0.05 & +15.23 \\
\hline
\end{tabular}

From this table, it can be observed that the addition of alum of $0.04 \mathrm{~g} / \mathrm{L}$ of water sample led to the decrease in value of its zeta potential to $-3.72 \mathrm{mV}$ and it is expected that at this concentration the maximum coagulation must have occurred. Various reports available in literature corroborate the fact that at maximum coagulation occurred at zeta potential ranging from -4 to $+3 \mathrm{mV}$ [25-27].

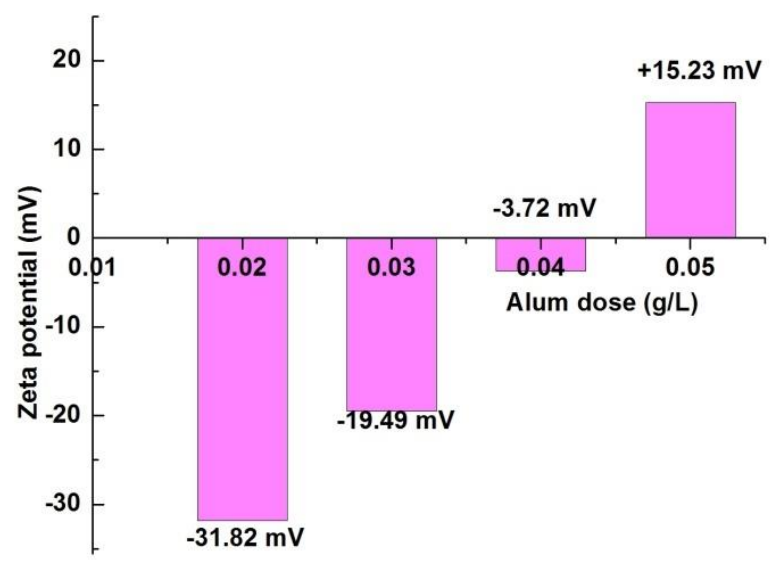

Figure 1: Variation in zeta potential of waste water with variation in alum dose

\subsection{Effect of chitosan concentration on zeta potential}

Zeta potentials of the supernatants obtained from various samples after treatment with different concentrations of chitosan $(0.1-0.5 \mathrm{~g} / \mathrm{L})$ were recorded and the results are summed in Table 3.

Table 3: Variation in zeta potential of waste water with variation in chitosan concentration

\begin{tabular}{ll}
\hline CH concentration $(\mathbf{g} / \mathbf{L})$ & Zeta potential $(\mathbf{m V})$ \\
\hline 0.0 (only alum) & -8 \\
0.1 & -12 \\
0.2 & -7.26 \\
$\mathbf{0 . 3}$ & $\mathbf{- 1 . 4 9}$ \\
0.4 & +3.45 \\
0.5 & +5.16 \\
\hline
\end{tabular}

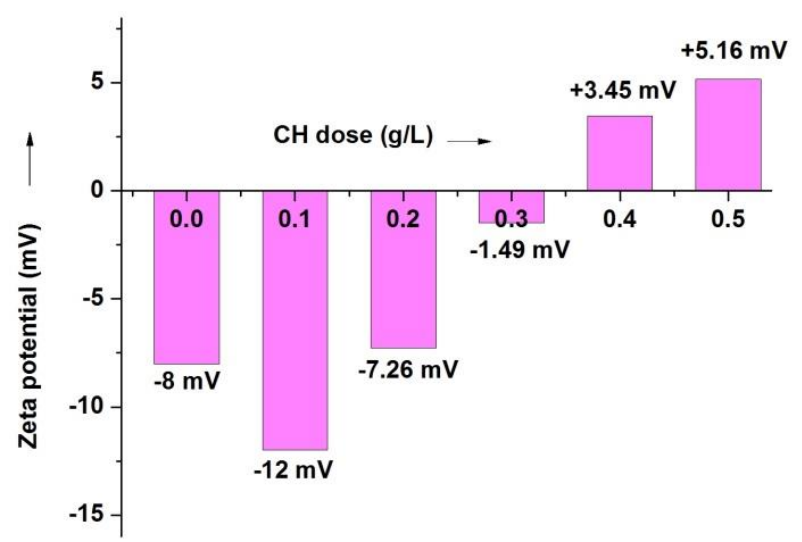

Figure 2: Effect of chitosan concentration on zeta potential

Fig. 2 shows the effect of various doses of chitosan on zeta potential of water sample. It was noticed that with increasing dose of chitosan, the zeta potential of the wastewater gradually changed from more negative to less negative and then shifted to a positive value. Analyzing the flocculation behavior of the samples it was observed that maximum flocculation occurred when the value of zeta potential was almost near to zero $(-1.49$ $\mathrm{mV}$ ) and the corresponding $\mathrm{CH}$ concentration was $0.3 \mathrm{~g} / \mathrm{L}$. Further increase in $\mathrm{CH}$ concentration enhanced the zeta potential which may be attributed to excess adsorption of chitosan on the colloidal impurities leading to charge reversal. Similar results have been reported in the literature [28, 29].

\subsection{Effect of chitosan concentration on $\mathrm{pH}$}

$\mathrm{pH}$ was monitored for all samples and the results are presented in Table 4. It has been observed that as the concentration of chitosan increases, the $\mathrm{pH}$ of the solution shows a dropping trend but not in a much wide range. This may be due to preparation of $\mathrm{CH}$ solution in acidic medium in which chitosan acts a cationic bio-polymer owing to the presence of plentiful amine groups. The $\mathrm{pK}_{\mathrm{a}}$ for chitosan is typically $\sim 6.5$, which depends upon its degree of deacetylation. In general, when $\mathrm{pH}$ of solution exceeds $\mathrm{pK}_{\mathrm{a}}$ (chitosan) it does not dissolve in water and if $\mathrm{pH}$ value is less than $\mathrm{pK}_{\mathrm{a}}$ (chitosan), amine groups get protonated to form $-\mathrm{NH}_{3}{ }^{+}$, subsequently increasing attraction towards negatively charged impurities present in waste water [30, 31]. Further, at higher alkalinity, there is a 
reasonable tendency of deprotonation of the hydroxyl groups to generate negatively charged species. Thus, the $\mathrm{pH}$ for all the samples was maintained below 6.5. Fig. 3 depicts the decline in $\mathrm{pH}$ with $\mathrm{CH}$ concentration. The values signify that all the $\mathrm{CH}$ concentrations possess the capability to bridge with the impurities and the typical value of $\mathrm{pH}$ for optimum $\mathrm{CH}$ concentration is $0.3 \mathrm{~g} / \mathrm{L}$ is 6.08 .

Table 4: Variation in $\mathrm{pH}$ of the water samples with variation in chitosan concentration

\begin{tabular}{ll}
\hline CH concentration $(\mathbf{g} / \mathbf{L})$ & $\mathbf{p H}$ of solution \\
\hline 0.1 & 6.47 \\
0.2 & 6.37 \\
$\mathbf{0 . 3}$ & $\mathbf{6 . 0 8}$ \\
0.4 & 5.96 \\
0.5 & 5.89 \\
\hline
\end{tabular}

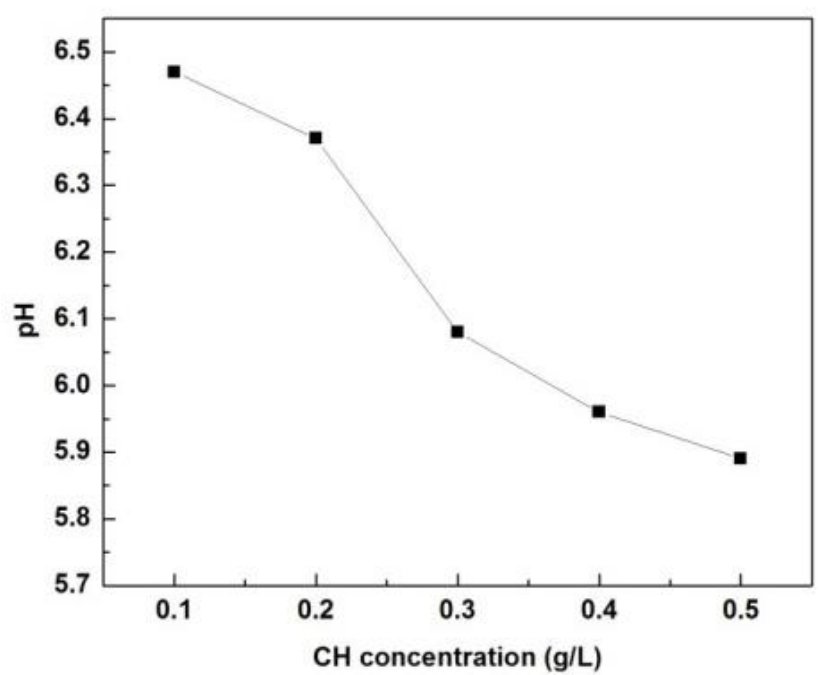

Figure 3: Variation in the $\mathrm{pH}$ of the solutions with variation in chitosan concentration

\subsection{Effect of chitosan concentration on COD}

The COD values of the untreated and treated effluents (water samples) were determined as per the methodology mentioned in section 2.2.1. The untreated effluent has a COD value of $2816 \mathrm{mg}$ of $\mathrm{O}_{2} / \mathrm{L}$ and the $\mathrm{COD}$ values and corresponding reduction after treatment with varying concentrations of chitosan are presented in Table 5. Fig. 4 shows the trend in COD reduction post chitosan treatment. The treatment with $\mathrm{CH}$ solution $(0.1 \mathrm{~g} / \mathrm{L})$ reduces the COD by $68.5 \%$ and a further increase in $\mathrm{CH}$ concentration enhances COD reduction up to $\mathrm{CH}$ concentration of $0.3 \mathrm{~g} / \mathrm{L}$ [29].

\subsection{Effect of chitosan concentration on absorbance}

UV-Visible absorption spectra of the chitosan treated effluent samples analyzed in the region of 200-600 nm are shown in Fig. 5. A noticeable reduction in absorbance in the region of 250-300 $\mathrm{nm}$ is observed by all the samples, indicating the presence of lignin-based compounds responsible for imparting dark color to the liquid effluent which gets adsorbed in this region. The major compounds absorbed by the bio- flocculant are phenol ( 220 nm), aromatic compounds (254 nm), and compounds derived from lignin $(\sim 280 \mathrm{~nm})$ [32]. The highest absorbance was exhibited by the sample with $0.3 \mathrm{~g} / \mathrm{L}$ chitosan concentration.

Table 5: Variation in COD of water samples with addition of different concentrations of chitosan

\begin{tabular}{|c|c|c|}
\hline $\begin{array}{l}\text { CH concentration } \\
(\mathrm{g} / \mathrm{L})\end{array}$ & $\begin{array}{c}\text { COD value } \\
\left(\mathrm{mg} \mathrm{O}_{2} / \mathrm{L}\right)\end{array}$ & $\begin{array}{l}\text { COD reduction } \\
(\%)\end{array}$ \\
\hline untreated waste water & 2816 & --- \\
\hline 0.0 (only alum) & 1019 & 63.8 \\
\hline 0.1 & 885 & 68.5 \\
\hline 0.2 & 795 & 71.7 \\
\hline 0.3 & 616 & 78.1 \\
\hline 0.4 & 684 & 75.7 \\
\hline 0.5 & 951 & 66.2 \\
\hline
\end{tabular}

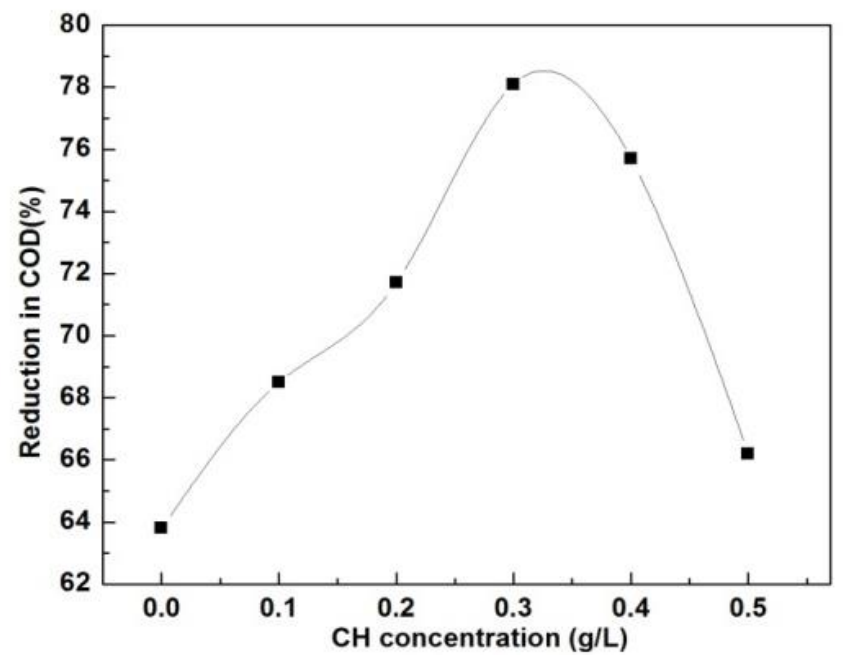

Figure 4: Percentage reduction in COD with varying chitosan concentration

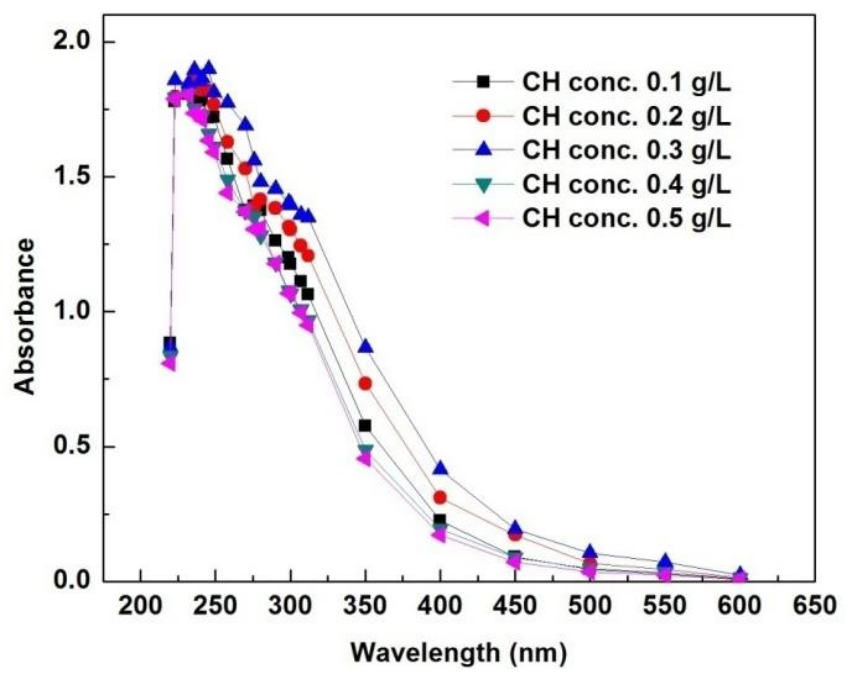

Figure 5: UV-Vis spectrum of wastewater with varying concentrations of chitosan 


\subsection{Effect of chitosan concentration on TSS}

Suspended impurities not only hamper the color and brightness of processed water but also affect its texture and promote the growth of slime. For this reason, the waste water sample after treatment with chitosan was analyzed for TSS removal. The TSS values thus obtained and their corresponding removal percentage are presented in Table 6 . It can be noticed that as the chitosan concentration is increased, the total suspended particle removal rate also improves, but after a certain dose of chitosan $(0.3 \mathrm{~g} / \mathrm{L})$ the TSS removal rate drops.

Table 6: Variation in the TSS of water sample with variation in

\begin{tabular}{lll}
\multicolumn{3}{c}{ chitosan concentration } \\
\hline CH concentration $(\mathbf{g} / \mathbf{L}))$ & TSS & TSS removal $(\%)$ \\
\hline 0.1 & 515 & 25 \\
0.2 & 627 & 31 \\
$\mathbf{0 . 3}$ & $\mathbf{1 6 3 5}$ & $\mathbf{8 1}$ \\
0.4 & 1587 & 78 \\
0.5 & 1550 & 76 \\
\hline
\end{tabular}

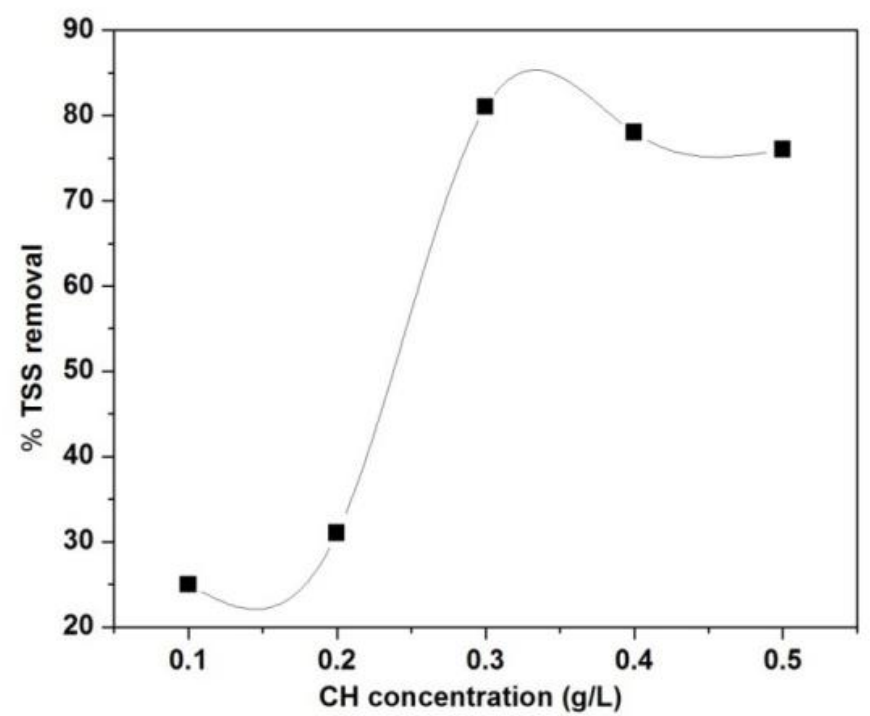

Figure 6: Percentage TSS removal with varying concentration of chitosan

Fig. 6 shows that the removal efficiencies of TSS with chitosan flocculant are attained upto $81 \%$. The removal rate of contaminant particles from waste water is proportional to the number of particles $(\mathrm{N})$, time $(\mathrm{t})$, and the fraction of successful collisions $(\alpha)$. It can be determined from the following equation:

$$
\frac{d N}{d t}=\alpha \times K \times(N)^{2}
$$

where $K$ is the mixed rate constant [28]. From the above equation, it is quite rational that higher the collision frequency between the coagulant and/or flocculant and suspended particles better would be the coagulation-flocculation process. The high efficiency of $\mathrm{CH}$ concentration of $0.3 \mathrm{~g} / \mathrm{L}$ in the TSS removal may be due to the high collision frequency between the chitosan and suspended solid particles [33]. However, as the chitosan dose was further increased, it led to reduction in removal percentage of TSS. This behavior may be attributed to the reversal of surface charge leading to restabilization of the coagulated particles. This may be further explained due to the unavailability of sites for bridge formation by polymers, resulting in steric repulsion [34].

\section{Conclusions}

The treatment of pulp and paper mill waste water has been attempted with conventional coagulant alum and a natural biodegradable polymeric flocculant, chitosan. The alum dose was optimized through zeta potential measurement which was found to be $0.04 \mathrm{~g} / \mathrm{L}$. Maximum reduction in COD was obtained at chitosan concentration of $0.3 \mathrm{~g} / \mathrm{L}$ and a further increase in dose did not improve the reduction efficiency. Also, a decrease in absorbance was observed in the UV-Vis spectra in the range of 200-300 nm for all the samples indicating the absorption of phenolics, lignin, and other aromatics in this wavelength region. Further, the TSS was reduced when the chitosan dose was increased stepwise. The maximum removal efficiency was exhibited at $\mathrm{CH}$ concentration of $0.3 \mathrm{~g} / \mathrm{L}$ in the solution. Besides, with the increasing dose of chitosan $(0.1$ to $0.5 \mathrm{~g} / \mathrm{L})$, the zeta potential of the sample gradually changed from negative to near zero and then shifted to positive. At high doses of chitosan, the sign of zeta potential is reversed due to excess adsorption of chitosan on the negatively charged colloidal impurities. At the flocculant concentration of $0.3 \mathrm{~g} / \mathrm{L}$, maximum $81 \%$ TSS and maximum $78 \%$ COD were reduced. Overall it can be said that the utilization of chitosan along with alum may be a better option for the treatment of pulp and paper wastewater as well as other similar types of wastewater.

\section{Acknowledgments}

The authors want to acknowledge ShaheedBhagat Singh State technical campus, Ferozepur for providing instrumental facilities.

\section{Ethical issue}

Authors are aware of, and comply with, best practice in publication ethics specifically with regard to authorship (avoidance of guest authorship), dual submission, manipulation of figures, competing interests and compliance with policies on research ethics. Authors adhere to publication requirements that submitted work is original and has not been published elsewhere in any language.

\section{Competing interests}

The authors declare that there is no conflict of interest that would prejudice the impartiality of this scientific work.

\section{Authors' contribution}

All authors of this study have a complete contribution for data collection, data analyses and manuscript writing.

\section{References}

[1] Hubbe MA, Metts JR, Hermosilla D, Blanco MA, Yerushalmi L, Haghighat $F$, et al. Wastewater treatment and reclamation: A review of pulp and paper industry practices and opportunities. Bioresources. 2016;11:7953-8091.

[2] Thapliyal B, Tyagi S. Water pinch analysis — an innovative approach towards water conservation in pulp and paper industry. IPPTA. 2015;27:59-66. 
[3] Pokhrel D, Viraraghavan T. Treatment of pulp and paper mill wastewater - a review. Science of the Total Environment 2004;333:37-58

[4] Ghosh U. Short sequence environment friendly bleaching of wheat straw pulp.Journal of Scientific and Industrial Research. 2006;65(01):68-71.

[5] Kaur D, Bhardwaj NK, Lohchab RK. A study on pulping of rice straw and impact of incorporation of chlorine dioxide during bleaching on pulp properties and effluents characteristics. Journal of Cleaner Production. 2018;170:174-82.

[6] González-García S, Hospido A, Moreira MT, Romero J, Feijoo G. Environmental impact assessment of total chlorine free pulp from Eucalyptus globulus in Spain. Journal of Cleaner Production. 2009;17:1010-6.

[7] Mark Hewitt L, Parrott JL, McMaster ME. A decade of research on the environmental impacts of pulp and paper mill effluents in Canada: sources and characteristics of bioactive substances. Journal of Toxicology and Environmental Health, Part B. 2006;9:341-56.

[8] McMaster ME, Mark Hewitt L, Parrott JL. A decade of research on the environmental impacts of pulp and paper mill effluents in Canada: field studies and mechanistic research. Journal of Toxicology and Environmental Health, Part B. 2006;9:319-39.

[9] Ali M, Sreekrishnan T. Aquatic toxicity from pulp and paper mill effluents: A review. Advances in Environmental Research. 2001;5:175-96.

[10] Lacorte S, Latorre A, Barcelo D, Rigol A, Malmqvist A, Welander T. Organic compounds in paper-mill process waters and effluents. TrAC Trends in Analytical Chemistry. 2003;22:725-37.

[11] Loganathan P, Gradzielski M, Bustamante H, Vigneswaran S. Progress, challenges, and opportunities in enhancing NOM flocculation using chemically modified chitosan: A review towards future development. Environmental Science: Water Research \& Technology. 2020;6:45-61.

[12] Ferasat Z, Panahi R, Mokhtarani B. Natural polymer matrix as safe flocculant to remove turbidity from kaolin suspension: Performance and governing mechanism. Journal of Environmental Management. 2020;255:109939.

[13] Xiuli Z, Fengshan Z, Wenxiu S. Treatment of paper making wastewater with polyaluminum chloride-polyacrylamide composite flocculant. Industrial Water Treatment-Tianjin 2005;25:36.

[14] Ngo H-H, Guo W. Membrane fouling control and enhanced phosphorus removal in an aerated submerged membrane bioreactor using modified green bioflocculant. Bioresource Technology. 2009;100:4289-91.

[15] Lichtfouse E, Morin-Crini N, Fourmentin M, Zemmouri H, do Carmo Nascimento IO, Queiroz LM, et al. Chitosan for direct bioflocculation of wastewater. Environmental Chemistry Letters. 2019:1-19.

[16] Morin-Crini N, Lichtfouse E, Torri G, Crini G. Applications of chitosan in food, pharmaceuticals, medicine, cosmetics, agriculture, textiles, pulp and paper, biotechnology, and environmental chemistry. Environmental Chemistry Letters. 2019:1-26.

[17] Kanmani P, Aravind J, Kamaraj M, Sureshbabu P, Karthikeyan S. Environmental applications of chitosan and cellulosic biopolymers: A comprehensive outlook. Bioresource Technology. 2017;242:295303.

[18] Desbrières J, Guibal E. Chitosan for wastewater treatment. Polymer International. 2018;67:7-14.

[19] Vidal R, Moraes J. Removal of organic pollutants from wastewater using chitosan: a literature review. International Journal of Environmental Science and Technology. 2019;16:1741-54.

[20] Renault F, Sancey B, Charles J, Morin-Crini N, Badot P-M Winterton $\mathrm{P}$, et al. Chitosan flocculation of cardboard-mill secondary biological wastewater. Chemical Engineering Journal. 2009; $155: 775-83$

[21] Picos-Corrales LA, Sarmiento-Sánchez JI, Ruelas-Leyva JP, Crini Gg, Hermosillo-Ochoa E, Gutierrez-Montes JA. Environmentfriendly approach toward the treatment of raw agricultural wastewater and river water via flocculation using chitosan and bean straw flour as bioflocculants. ACS omega. 2020;5:3943-51.

[22] Altaher $\mathrm{H}$. The use of chitosan as a coagulant in the pre-treatment of turbid sea water. Journal of Hazardous Materials. 2012;233:97102.

[23] Meraz KAS, Vargas SMP, Maldonado JTL, Bravo JMC, Guzman MTO, Maldonado EAL. Eco-friendly innovation for nejayote coagulation-flocculation process using chitosan: Evaluation through zeta potential measurements. Chemical Engineering Journal 2016;284:536-42.

[24] APHA AW, W. Standard methods for the examination. Water and Wastewater 20th ed, American Public Health Association, Washington, DC. 2000

[25] Amirtharajah A, Clark MM, Trussell RR. Mixing in coagulation and flocculation: AWWA research foundation, Colarado; 1991.

[26] Kim TH, Park C, Kim S. Comparison of disperse and reactive dye removals by chemical coagulation and Fenton oxidation. Journal of Hazardous Materials. 2004;112:95-103.

[27] Barzegari Z, Bina B, Pourzamani H, Ebrahimi A. The combined treatment of bisphenol A (BPA) by coagulation/flocculation $(\mathrm{C} / \mathrm{F})$ process and UV irradiation in aqueous solutions. Desalination and Water Treatment. 2016;57:8802-8.

[28] Wong S, Teng T, Ahmad A, Zuhairi A, Najafpour G. Treatment of pulp and paper mill wastewater by polyacrylamide (PAM) in polymer induced flocculation. Journal of Hazardous Materials. 2006; $135: 378-88$

[29] Solberg D, Wågberg L. Adsorption and flocculation behavior of cationic polyacrylamide and colloidal silica. Colloids and Surfaces A: Physicochemical and Engineering Aspects. 2003;219:161-72.

[30] Bhalkaran S, Wilson LD. Investigation of self-assembly processes for chitosan-based coagulant-flocculant systems: A mini-review. International Journal of Molecular Sciences. 2016;17:1662.

[31] Aili D, Feraoun I, Adour L, Lounici H. Use of dispersed and beads chitosan in liquid effluents treatment. Process Engineering Journal. 2017; 2:41-51.

[32] Aravind U, George B, Baburaj M, Thomas S, Thomas A, Aravindakumar C. Treatment of industrial effluents using polyelectrolyte membranes. Desalination. 2010;252:27-32.

[33] Hassan MAA, Hui LS, Noor ZZ. Removal of boron from industrial wastewater by chitosan via chemical precipitation. Journal of Chemical and Natural Resources Engineering. 2009;4:1-11.

[34] Weber WJ. Physiochemical processes for water qualitycontrol. Wiley, New York, 1972. 